\title{
A naturalistic study of the word frequency effect in episodic recognition
}

\author{
KERRY A. CHALMERS, MICHAEL S. HUMPHREYS, and SIMON DENNIS \\ University of Queensland, Brisbane, Queensland, Australia
}

\begin{abstract}
In order to separate the effects of experience from other characteristics of word frequency (e.g., orthographic distinctiveness), computer science and psychology students rated their experience with computer science technical items and nontechnical items from a wide range of word frequencies prior to being tested for recognition memory of the rated items. For nontechnical items, there was a curvilinear relationship between recognition accuracy and word frequency for both groups of students. The usual superiority of low-frequency words was demonstrated and high-frequency words were recognized least well. For technical items, a similar curvilinear relationship was evident for the psychology students, but for the computer science students, recognition accuracy was inversely related to word frequency. The ratings data showed that subjective experience rather than background word frequency was the better predictor of recognition accuracy.
\end{abstract}

Gorman (1961) was one of the first to report on the superior recognition of low- over high-frequency words. The low-frequency advantage in recognition has since been confirmed in a number of studies over a range of conditions and manipulations (see Glanzer \& Adams, 1985, for a review). When word frequency effects are studied over a larger range of frequencies (not just low vs. high), the relationship between frequency and accuracy is an inverted U-shaped function (Wixted, 1992; Zechmeister, Curt, \& Sebastian, 1978). Recognition is highest for lowfrequency words and decreases as word frequency either increases or decreases. Nonwords are assumed to be poorly recognized either because they have no meaning or because they have never been encountered prior to the experiment. Although poor recognition of very low-frequency words has been linked to low ratings of lexicality (Schulman, 1976) and to low ratings of meaningfulness and familiarity (Zechmeister et al., 1978), the influence of these experiential factors has not been separated from other correlates of word frequency (e.g., phonemic and graphemic composition). ${ }^{1}$

Allen and Garton (1968) adopted a naturalistic approach in their investigation of the word frequency effect. They compared physics and arts students' recognition memory for two classes of words: physics technical words (expected to be in the ordinary vocabulary of the physics but not the arts students) and common words (Thorndike \& Lorge, 1944, rating of 30 or more). Their results showed the usual word frequency effect in that the lower frequency physics words were recognized better

This work was part of K.A.C.'s PhD research. It was supported by an Australian Postgraduate Research Award to K.A.C. We would like to thank Geoffrey Loftus and two anonymous reviewers for helpful comments on an earlier draft. Correspondence should be directed to $\mathrm{K}$. A. Chalmers, Department of Psychology, University of Queensland, Brisbane, QLD 4072, Australia (e-mail: kerry@psy.uq.edu.au). than were the common words by both physics and arts students. Recognition of physics words, however, was significantly higher for physics students than for arts students. Allen and Garton assumed that the physics words were rare to both groups of students, but that their meaning was rare only to the arts students. They attributed the superior recognition of physics words by the physics students to this difference in knowledge of the meaning.

One difficulty in evaluating Allen and Garton's (1968) results is that normative word frequency and word type were confounded in their study. All rare words were physics words; all common words were nontechnical words. We cannot be sure whether the superior performance of physics students on physics words was due to the physics words' being like nonwords to the arts students (i.e., having never been used or encountered prior to the experiment) or whether some kind of domain-specific information was available to the physics students that was not available to the arts students.

The present study is based on the naturalistic approach used by Allen and Garton (1968). The advantage of this approach is that between-group differences in preexperimental familiarity occur naturally, and because the same materials are used for both groups, there is no confounding of structural word characteristics and word frequency. Two groups of university students (computer science and psychology students) whose learning history would be expected to produce differential experience with computer science technical items performed recognition judgments on verbal items from two different classes: items with a technical meaning in computer science (CS-tech) and items that were nontechnical (nontech). The items in each class were distributed over a continuous range of word frequencies based on Kučera and Francis (1967) norms. An example of each item class is shown in Table 1. At the lowest frequency level, the nontech items were nonwords. They had no meaning and were formed by substi- 
tuting or rearranging one or two letters of real English words. The CS-tech items at the lowest frequency level did have a meaning in computer science, but were essentially nonwords to people outside that discipline. These items had no frequency rating in the Kučera and Francis norms and (for brevity) are referred to throughout this paper as "zero-frequency CS-tech items." The low-, medium-, and high-frequency CS-tech items had meanings in computer science, as well as meanings in everyday English.

The present design allowed us to separate the role of experience from the influence of structural correlates of word frequency by holding the materials (i.e., CS-tech items) constant and varying preexperimental experience (computer science vs. psychology students). By including both CS-tech and nontech items from a range of word frequencies (from 0 to 400 words per million) and having participants rate their experience with the items, we can investigate the role of experience in the curvilinear relationship between word frequency and recognition accuracy. The ratings data will also help to establish whether the type of learning that occurs when technical terms are encountered by students can change a zerofrequency word (i.e., no rating in the Kučera \& Francis, 1967 , norms) into a low-frequency word, or a lowfrequency word into a high-frequency word.

For the nontech items, we expected the usual curvilinear relationship between word frequency and recognition accuracy for both computer science and psychology students. If the zero-frequency CS-tech items are like nonwords to the psychology students, we would also expect a curvilinear relationship between word frequency and recognition accuracy for psychology students on the CStech items. If the superior performance of physics students on physics words in Allen and Garton's (1968) study was due to some overall advantage of physics students on physics words (not just to their being like nonwords to the arts students), we would expect computer science students to perform better than psychology students on CS-tech items at all levels of word frequency. Alternatively, if computer science students' experience with CStech items has increased their functional word frequency (making zero-frequency items like low-frequency words, and low-frequency items like high-frequency words), we would expect recognition accuracy to be inversely related to word frequency (i.e., in the order zero, low, medium, and high frequency).

To summarize, there were two main objectives of the study. The first objective was to separate the effects of

Table 1

Examples of Computer Science Technical (CS-Tech) and Nontechnical (Nontech) Items

\begin{tabular}{ccl} 
& \multicolumn{2}{c}{ Item Type } \\
\cline { 2 - 3 } Word Frequency & CS-Tech & Nontech \\
\hline Zero & grep & vort \\
Low & user & apex \\
Medium & loop & beam \\
High & file & face \\
\hline
\end{tabular}

prior experience from the physical characteristics of word frequency (e.g., orthographic distinctiveness) by holding the materials constant and comparing students who differed in their preexperimental experience with these materials. The second objective was to examine the ratings data to find out what participants can report about their preexperimental experience with the items and to see how this report relates to performance.

\section{METHOD}

\section{Subjects}

Ninety-two students from the University of Queensland volunteered to participate in the experiment; half were from a third-level computer science class and half from a third-level psychology class. Testing was carried out in large groups during normal class time.

\section{Design}

The design was a $2 \times 2 \times(2 \times 4)$ factorial with study list (A vs. B) and group (computer science vs. psychology) as between-subjects factors and item type (CS-tech vs. nontech) and word frequency (zero, low, medium, and high frequency) as within-subjects factors.

\section{Stimuli}

The stimuli were $30 \mathrm{CS}$-tech and 30 nontech items from each of four levels of word frequency based on the Kučera and Francis (1967) norms: high, more than 40 occurrences per million $(M=$ $134)$; medium, 11-40 per million $(M=20)$; low, $1-10$ per million $(M=4)$; and zero frequency (i.e., no rating in Kučera and Francis). The CS-tech items were drawn from the glossaries of two introductory textbooks on computer programming (Decker \& Hirshfield, 1992; Leestma \& Nyhoff, 1990) and a Unix systems guide (Sobell, 1989). Each low-, medium-, and high-frequency CS-tech item was matched with a nontech item of the same frequency, length, and number of syllables. Each zero-frequency CS-tech item was matched with a nonword of the same length and number of syllables. ${ }^{2}$ The words were divided into two alternate study lists (A and B). Each list had 15 items from each class. The lists were equated for word length and number of syllables.

\section{Procedure}

Half of the participants in each group rated List A, and half rated List B. The recognition test consisted of all 240 items from the complete set so that targets for half the participants were distractors for the other half. The order of items within the ratings and recognition tasks was completely randomized for each participant. Both study and test items were presented in booklet form. The items were described as letter strings, some of which were technical words, some ordinary words, and some nonsense words. The cover page instructed participants that they would have $5 \mathrm{~min}$ to rate the items on the following three pages on a 3-point scale of preexperimental experience $(0$, never encountered the item before; 1 , encountered the item but rarely used it; 2 , encountered and used the item frequently). The rating scale was reprinted on a separate slip of paper and participants were told to place this slip in front of them while rating the items. They were instructed not to look ahead or backward once they began to rate the items. No mention of a memory test was made. Items were arranged in two columns of 28 items per page with the 3-point rating scale printed beside each of the 120 study items and yes/no after each item in the recognition test. A page instructing participants not to turn the page was inserted between the three pages of the ratings task and the instructions for the recognition test. Participants were notified when $1 \mathrm{~min}$ remained on the ratings task. When $5 \mathrm{~min}$ had elapsed, participants proceeded to the recognition test, which required them to indicate by circling either yes or no whether an item had been presented for rating in the previous task. There were no time restrictions on the recognition task. After the 
recognition task, participants completed a brief questionnaire about their course of study and computer programming experience. Participants were assigned to one of two groups on the basis of responses to the questionnaire: Computer science students with more than 2 years of computer programming experience; or psychology students with less than 1 year of programming experience. The data of 10 computer science and 10 psychology students were excluded because they failed to meet these criteria.

\section{RESULTS AND DISCUSSION}

Estimates of $d^{\prime}$, calculated from the hit and false alarm rate data of individual participants, are presented in Figure $1 .{ }^{3}$ These data show the same pattern of results as that reported by Allen and Garton (1968). First, recognition of zero-frequency CS-tech items was significantly 4 higher for computer science students than for psychology students $\left[F(1,70)=14.43, M S_{\mathrm{e}}=.32\right]$, similar to the superior recognition of physics words by physics students in Allen and Garton's study. Second, both computer science and psychology students performed significantly better on the zero-frequency CS-tech items than on the high-frequency nontech items $\left[F(1,35)=42.96, M S_{\mathrm{e}}=\right.$ .23 , and $F(1,35)=7.34, M S_{\mathrm{e}}=.32$, for computer science and psychology students, respectively], similar to Allen and Garton's finding that both physics and arts students performed better on physics than on common words. These findings demonstrate the generality of Allen and Garton's results for both physics and computer science materials. As we have already mentioned, however, Allen and Garton used only two item classes in their study (rare technical words and common words). Examining performance over a larger range of word frequencies should yield a better understanding of the role of experience in producing these effects.

Figure 1 shows that when the range of word frequencies (from zero to high frequency) is considered, there is a curvilinear relationship between word frequency and $d^{\prime}$ for both groups on the nontech items and for the psychology students on the CS-tech items. Recognition was highest for low-frequency words, and lowest for highfrequency words, following the inverted U-shape curve reported in previous research (e.g., Wixted, 1992; Zechmeister et al., 1978). For the computer science students, however, recognition accuracy for CS-tech items was inversely related to word frequency, with highest performance on zero-frequency CS-tech items. These data suggest that experience, rather than the physical characteristics of verbal items, is a more important determinant of the word frequency effect because the same items (i.e., CS-tech items) led to different results for computer science and psychology students.

The idea that the superior recognition of zero-frequency CS-tech items by computer science students is due to some kind of domain-specific information is not supported by these results: The computer science students did not perform better than the psychology students over the range of CS-tech items. As we have already noted, computer science students performed significantly better than psychology students on zero-frequency CS-tech items. How-
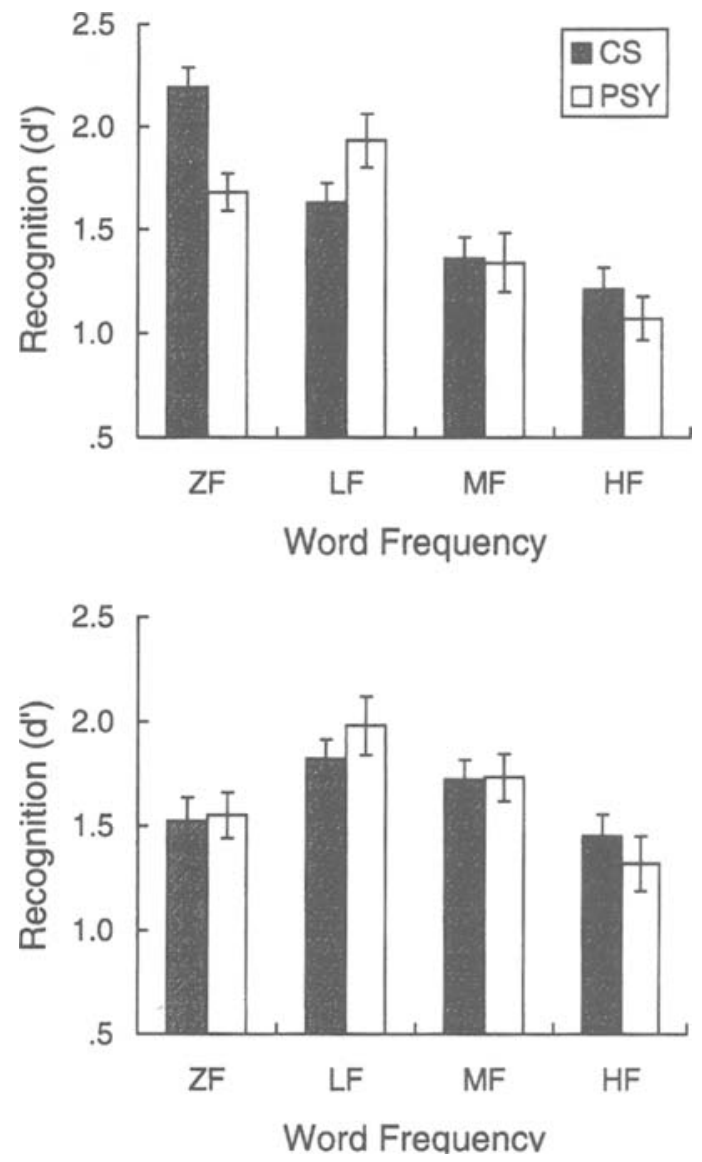

Figure 1. Recognition $\left(d^{\prime}\right)$ of computer science technical (upper panel) and nontechnical (lower panel) items for computer science (CS) and psychology (PSY) students. Vertical bars represent $S E M$.

ever, this pattern was reversed for low-frequency CS-tech items. On these items, computer science students performed worse than psychology students, and this difference was almost significant $(p<.07)$.

To investigate whether the additional experience of computer science students with CS-tech items may have increased their functional word frequency, we compared recognition of zero- and low-frequency CS-tech and nontech items separately for each group. Computer science students' recognition of zero-frequency CS-tech items was significantly better than their recognition of zero-frequency nontech items $\left[F(1,35)=19.86, M S_{\mathrm{e}}=\right.$ $.40]$, whereas psychology students' recognition of zerofrequency CS-tech items did not differ significantly from their recognition of zero-frequency nontech items. This pattern of results suggests that zero-frequency CS-tech items may have seemed like nonwords to the psychology students, but like low-frequency words to the computer science students.

Computer science students' recognition of lowfrequency CS-tech items tended to be worse than their recognition of low-frequency nontech items, although this difference was only marginally significant $[F(1,35)=4.03$, 
Table 2

Mean Ratings of Experience and Standard Errors for Computer Science Technical and Nontechnical Items

\begin{tabular}{|c|c|c|c|c|c|c|c|c|}
\hline \multirow[b]{3}{*}{ Group } & \multicolumn{8}{|c|}{ Word Frequency } \\
\hline & \multicolumn{2}{|c|}{$\mathrm{ZF}$} & \multicolumn{2}{|c|}{$\mathrm{LF}$} & \multicolumn{2}{|c|}{ MF } & \multicolumn{2}{|c|}{$\mathrm{HF}$} \\
\hline & $M$ & $\overrightarrow{S E}$ & $M$ & $S E$ & $M$ & $S E$ & $M$ & $S E$ \\
\hline \multicolumn{9}{|c|}{ Computer Science Technical Items } \\
\hline Computer Science & 1.36 & .05 & 1.82 & .03 & 1.86 & .03 & 1.93 & .03 \\
\hline Psychology & 0.36 & .02 & 1.47 & .04 & 1.80 & .03 & 1.93 & .0 \\
\hline \multicolumn{9}{|c|}{ Nontechnical Items } \\
\hline Computer Science & 0.05 & .01 & 1.34 & .06 & 1.54 & .06 & 1.77 & .05 \\
\hline Psychology & 0.04 & .01 & 1.47 & .04 & 1.68 & .04 & 1.93 & .02 \\
\hline
\end{tabular}

Note-ZF, zero frequency; LF, low frequency; MF, medium frequency; $\mathrm{HF}$, high frequency.

$\left.M S_{\mathrm{e}}=.16, p=.05\right]$. This finding suggests that the lowfrequency CS-tech items may have seemed more like medium- or high-frequency words to computer science students. Psychology students' recognition of low-frequency CS-tech items did not differ significantly from their recognition of low-frequency nontech items, suggesting that low-frequency CS-tech items and low-frequency nontech words are functionally the same to this group.

\section{Ratings of Subjective Experience}

The recognition data suggest that computer science students' experience with CS-tech items may have increased their functional word frequency, making zerofrequency CS-tech items seem more like low-frequency words and low-frequency CS-tech items more like medium- or high-frequency words. Support for this conclusion comes from the ratings of subjective experience obtained in the study phase and presented in Table 2.5 The mean rating of zero-frequency CS-tech items was higher for computer science than for psychology students $\left[F(1,70)=435.89, M S_{\mathrm{e}}=.04\right]$. For computer science students, the mean rating of zero-frequency CS-tech items did not differ significantly from their rating of lowfrequency nontech items, whereas for psychology students, the mean rating of zero-frequency CS-tech items was significantly lower than their rating of low-frequency nontech items $\left[F(1,35)=658.14, M S_{\mathrm{e}}=.03\right]$. These results suggest that the zero-frequency CS-tech items seemed like nonwords to the psychology students, but like low-frequency words to the computer science students.

The mean rating of low-frequency CS-tech items was also higher for computer science than for psychology students $\left[F(1,70)=44.84, M S_{\mathrm{e}}=.05\right]$. Computer science students' rating of low-frequency CS-tech items did not differ significantly from their rating of high-frequency nontech items, whereas psychology students' rating of low-frequency CS-tech items was identical to their rating of low-frequency nontech items. These findings suggest that the low-frequency CS-tech items may seem more like medium- or high-frequency words to computer science students.

\section{Recognition as a Function of Subjective Rating}

The high level of performance of the computer science students on zero-frequency CS-tech items suggests that superior recognition might be related to the uniqueness or rarity of an item, but that this effect is mediated by an additional factor-whether or not the item has been previously encountered. To directly examine the relationship between rated experience and recognition, we calculated the proportion of correct responses for the nontech items as a function of subjective rating. ${ }^{6}$ These results are presented in Figure 2.

Recognition of items rated rarely was significantly better than that of items rated never $[F(1,67)=21.01$, $\left.M S_{\mathrm{e}}=.02\right]$ or of items rated frequently $[F(1,67)=23.91$, $\left.M S_{\mathrm{e}}=.02\right]$. These data indicate that episodic recognition of verbal items is sensitive to subjective estimates of prior experience. Items that are often used or encountered are poorly recognized. Items that are never used or encountered are also poorly recognized. Items that have been previously encountered, but not often used, are recognized best of all.

\section{Summary and Conclusion}

The purpose of this study was to investigate the role of preexperimental experience in producing word frequency effects in episodic recognition. The results support the hypothesis that when physical characteristics (e.g., phonemic and graphemic composition) are held constant, experience does have an important role; the same items (i.e., CS-tech items) led to a different pattern of results for computer science and psychology students. For computer science students, recognition of CS-tech items was inversely related to word frequency, whereas for psychology students, the relationship between frequency and accuracy was curvilinear. Analysis of the subjective ratings

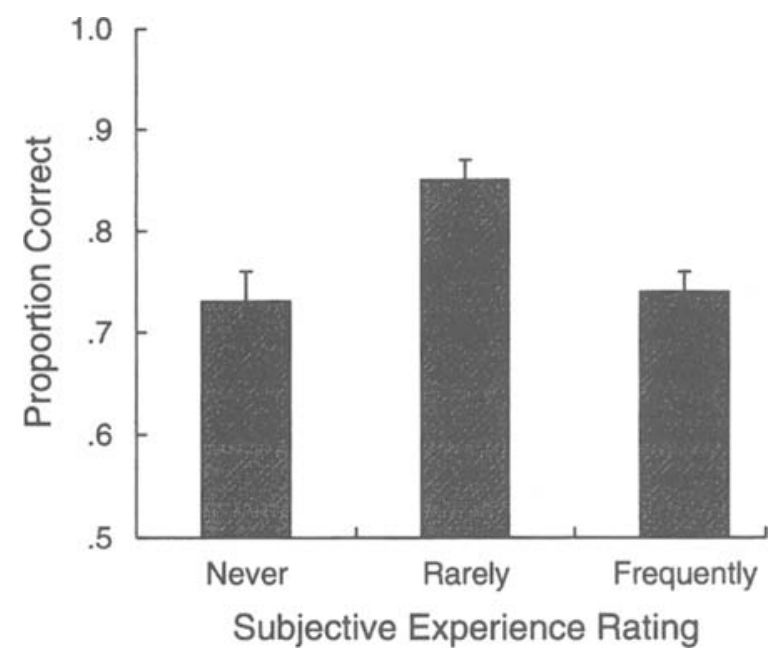

Figure 2. Proportion correct for nontechnical items as a function of subjective experience rating. Vertical bars represent $S E M$ s. Data are for 68 students who had a score in every cell. 
data indicates that these differences occurred because (1) the zero-frequency CS-tech items seemed like lowfrequency words to computer science students, but like nonwords to psychology students, and (2) low-frequency CS-tech items seemed like high-frequency words to computer science students, but like low-frequency words to psychology students.

The importance of experience in producing word frequency effects was also seen in recognition of nontech items as a function of subjective rating. The results confirmed what has been commonly assumed, but not fully tested in the literature: Subjective experience rather than background word frequency is the better predictor of recognition. Items that have never been encountered and items that are frequently encountered are poorly recognized, whereas items that have been encountered but are not often used are well recognized.

At this time it is not clear whether mere exposure (prior to the experiment) or knowledge of meaning is the important factor in producing these word frequency effects. The kind of learning that takes place when students encounter new technical words, however, is primarily definitional, occurring with relatively few exposures in a very limited number of contexts. The consequence of this learning appears to be a high degree of accuracy in episodic recognition judgments. The superior recognition of computer science technical items by the students with 2 years of training in computer programming has yielded some idea about how much learning, and of what kind, is needed to turn a poorly recognized nonword into a wellrecognized word or a low-frequency word into a mediumor high-frequency word.

\section{REFERENCES}

Allen, L. R., \& GarTon, R. F. (1968). The influence of knowledge on the word-frequency effect in recognition memory. Psychonomic Science, 10, 401-402.

DECKER, R., \& HiRSHFIEld, S. (1992). Pascal's triangle. Belmont, CA: Wadsworth

GL ANZER, M., \& ADAMS, J. K. (1985). The mirror effect in recognition memory. Memory \& Cognition, 13, 8-20.

Gorman, A. M. (1961). Recognition memory for nouns as a function of abstractness and frequency. Journal of Experimental Psychology, 61, 23-29.
GREGG, F. H. (1976). Word frequency, recognition and recall. In J. B Brown (Ed.), Recall and recognition (pp. 183-216). London: Wiley. Kučera, H., \& Francis, W. N. (1967). Computational analysis of present-day American English. Providence, RI: Brown University Press.

Leestma, S., \& Nyhoff, L. (1990). Turbo Pascal: Programming and problem solving. New York: Macmillan.

Schulman, A. I. (1976). Memory for rare words previously rated for familiarity. Journal of Experimental Psychology: Human Learning \& Memory, 2, 301-307.

Snodgrass, J. G., \& Corwin, J. (1988). Pragmatics of measuring recognition memory: Applications to dementia and amnesia. Journal of Experimental Psychology: General, 117, 34-50.

SOBELL, M. G. (1989). A practical guide to the Unix system (2nd ed.) Redwood City, CA: Benjamin/Cummings.

THORNDIKE, E. L., \& LoRGE, I. (1944). The teacher's word book of 30,000 words. New York: Columbia University, Teachers College Press.

WIXTED, J. T. (1992). Subjective memorability and the mirror effect Journal of Experimental Psychology: Learning, Memory, \& Cognition, 18, 681-690.

Zechmeister, E. B., Curt, C., \& Sebastian, J. A. (1978). Errors in a recognition memory task are a $U$-shaped function of word frequency. Bulletin of the Psychonomic Society, 11, 371-373.

\section{NOTES}

1. See Gregg (1976) for a review of the literature on word frequency and its correlates.

2. Not all of the zero-frequency CS-tech items were orthographically legal, so some nonwords with nonlegal orthography were also included

3 . Hits and false alarms were adjusted prior to calculation of $d^{\prime}$ according to the method described in Snodgrass and Corwin (1988). Adjusted hit rate $=($ hits +.5$) /(N+1)$; adjusted false alarm rate $=($ false alarms +.5$) /(N+1)$, where $N=$ number of observations. Preliminary analysis showed there was no effect of list, so scores were collapsed across lists.

4. Throughout the paper, tests yielding $p<.05$ are referred to as sig nificant; $p \geq .05$ is considered nonsignificant.

5. Mean rating of experience $=($ no. of never ratings $\times 0)+($ no. of rarely ratings $\times 1)+($ no. of frequently ratings $\times 2$ ).

6. As expected, many computer science students did not rate any of the CS-tech items as words they had never encountered before. Also, some participants consistently used only two of the three levels of subjective ratings. The analysis was therefore restricted to the nontech items and was conducted on the 68 subjects ( 34 in each group) who provided ratings at all levels of experience. The pattern of results was the same for both groups of students, so scores were collapsed across groups before analysis.

(Manuscript received May 10, 1996; revision accepted for publication October $4,1996$. 